\title{
Drug-induced jaw osteonecrosis
}

\author{
Girolamo Donati
}

Gastro-Oncological Surgery Department, Dentistry Operative Unit, ASST Fatebenefratelli Sacco, Milan, Italy

\begin{abstract}
Medication-related osteonecrosis of the jaw (MRONJ), an adverse reaction to medication, has been reported since 2002, at first in cancer patients with bone metastases treated intravenously with pamidronate or zoledronate, and later in patients taking oral bisphosphonate for the treatment of osteoporosis. Several cases of MRONJ have also been described in patients treated with antiangiogenic drugs with a so-called biological target (bevacizumab, sunitinib, sorafenib).

Oxygen/ozone therapy for MRONJ treatment represents a possible and efficient alternative to the two main therapeutic approaches currently in use, antibiotic therapy and surgery.

Since 2010, I have diagnosed 51 MRONJ cases at ASST Fatebenefratelli-Sacco. Subsequently and following the approval of the Ethics Committee (2015), patients with MRONJ level 1 and 2 have been included in an experimental protocol with oxygen/ozone therapy: Treatment of bisphosphonate-related osteonecrosis of the jaw with oxygen/ozone therapy and surgical debridement with piezoelectric scalpel.

The study is currently running and up to now six out of fourteen patients healed perfectly. Among these six, four spontaneously or almost spontaneously have expelled the necrotic part without undergoing surgery. In three cases, there was only an improvement in symptoms. Five patients are currently being treated. Because of its antiseptic properties, oxygen ozone therapy reduced the effects of infection and inflammation, while the bio stimulant action of this therapy promoted the demarcation of bone sequestration and soft tissue healing.
\end{abstract}

Correspondence: Girolamo Donati, Gastro-Oncological-Surgical Department, Dentistry Operative Unit, ASST Fatebenefratelli Sacco, Milan, Italy.

Email: donati.girolamo@asst-fbf-sacco.it

Key words: Medication-related osteonecrosis of the jaw (MRONJ); oxygen/ozone therapy.

Received for publication: 12 November 2019.

Accepted for publication: 12 November 2019.

${ }^{\circ}$ Copyright: the Author(s), 2019

Licensee PAGEPress, Italy

Ozone Therapy 2019; 4:8698

doi:10.4081/ozone.2019.8698

This article is distributed under the terms of the Creative Commons Attribution Noncommercial License (by-nc 4.0) which permits any noncommercial use, distribution, and reproduction in any medium, provided the original author(s) and source are credited.

\section{Definition of osteonecrosis}

Medication related osteonecrosis of the jaw (MRONJ), an adverse reaction to medication, has been reported since 2002, at first in cancer patients with bone metastases treated intravenously with pamidronate or zoledronate and later in patients taking oral bisphosphonate for the treatment of osteoporosis. Several cases of MRONJ have also been described in patients treated with antiangiogenic drugs with a so-called biological target (bevacizumab, sunitinib, sorafenib). ${ }^{1-34}$ Antiresorptive drugs (bisphosphonates and denosumab) are used in metabolic and oncological pathologies involving the skeletal system, including bone metastases, neoplastic hypercalcemia, Paget's disease and imperfect osteogenesis. ${ }^{31,32}$ MRONJ is defined as: a diffuse maxillary disease characterized by the presence of bone exposed in the orofacial area, which does not tend to heal after eight weeks of observation and conventional therapy, in a patient treated with antiresorptive drugs and/or with anti-angiogenic activity, with no history of radiotherapy in the head and neck area. $^{34}$

The incidence of MRONJ varies from 1.2 to $9.9 \%$ and generally depends on the dose, the duration of the therapy and the route of administration of the drug (the parenteral route has a greater risk factor than the oral route). ${ }^{33}$ In most cases, this situation occurs after a surgical operation in the oral cavity e.g. the extraction of a tooth or the insertion of an implant. The onset of MRONJ is assisted by antiblastic therapy (chemotherapy, cortisone), debilitating diseases (e.g. infections, coagulopathies), poor oral hygiene and chronic periodontal disease. There have been reports of cases of MRONJ due to the trauma caused by the decubitus of incongruous prostheses. The exact mechanism that leads to bone necrosis is not completely known: bisphosphonates interfere with bone remodelling and lead to hypovascularisation. ${ }^{33}$ Medicationrelated osteonecrosis of the jaw presents with recurrent abscesses and pain in the mouth resistant to antibiotic and anti-inflammatory therapies. The patient also complains of difficulty in eating. On physical examination, very often, a fragment of necrotic bone (grey, non-vascularised) emerging from the gum can be identified. Osteonecrosis is considered a disease that can significantly reduce the quality of life of patients..$^{8,29}$

Prevention of MRONJ is based on measures such as careful oral hygiene, suitable periodontal therapy, prophylaxis for surgical procedures and monitoring of the subject (Table 1 and Figure 1). ${ }^{32,33}$

\section{Osteonecrosis therapy}

The two main therapeutic approaches for the treatment of this disease are, to date, antibiotic therapy and surgery. ${ }^{30}$ Antibiotic 
therapy is useful to control the symptoms but has limited effectiveness in time and above all does not solve the pathology. The surgical approach to osteonecrosis involves the removal of the necrotic part and presents the risk of relapse with extension of the areas of exposed bone and aggravation of the symptomatology. 3,29

\section{Oxygen/ozone therapy in the treatment of medication-related osteonecrosis of the jaw}

In the literature, alternative experimental therapeutic procedures have been tested on patients such as the use of hyperbaric oxygen,

Table 1. Clinical and radiological staging system for BRONJ (bisphosphonate related osteonecrosis of the jaw) (SICMF-SIPMO).

\section{Stage 1: FOCAL BRONJ}

In the presence of at least 1 minor clinical sign and with a bone thickening on CT limited only to the den to-alveolar process of the jaw or maxilla, with or without other early radiological signs.

Minor clinical signs and symptoms: halitosis, odontogenic abscess, mandibular asymmetry, tooth and bone pain, bone exposure, mucous fistula, failure of postextraction alveolar mucosa to heal, rapid onset tooth mobility, paraesthesia / dysesthesia of the lips, purulent discharge, spontaneous sequestration of bone fragments, trismus and swelling of soft tissues.

CT signs: trabecular thickening, focal medullary osteosclerosis, with or without thickening of the alveolar crest and lamina dura, persistence of post-extraction socket and widening of periodontal space.

a. Asymptomatic

b. Symptomatic (presence of pain and / suppuration)

\section{Stage 2: DIFFUSE BRONJ}

In the presence of at least one minor clinical sign and with a bone thickening on the CT, extending also to the basal process of the mandible or maxilla, with or without late radiological signs.

Minor clinical signs and symptoms: as in stage 1 .

CT signs: diffuse osteosclerosis with or without orofroral and oronasal fistula, thickening of the alveolar canal, periosteal reaction, sequestration and sinusitis.

a. Asymptomatic

b. Symptomatic (presence of pain and / suppuration)

\section{Stage 3: COMPLICAIED BRONJ}

As in stage 2, in the presence of one or more of the following:

Minor clinical signs: extra-oral fistula, leakage of nasal fluids, preternatural mobility of the jaw with or without conserved occlusion.

CT signs: cutaneous mucus fistula, pathological fracture, osteolysis extended to the maxillary sinus, zygomatic and/or hard palate osteosclerosis.
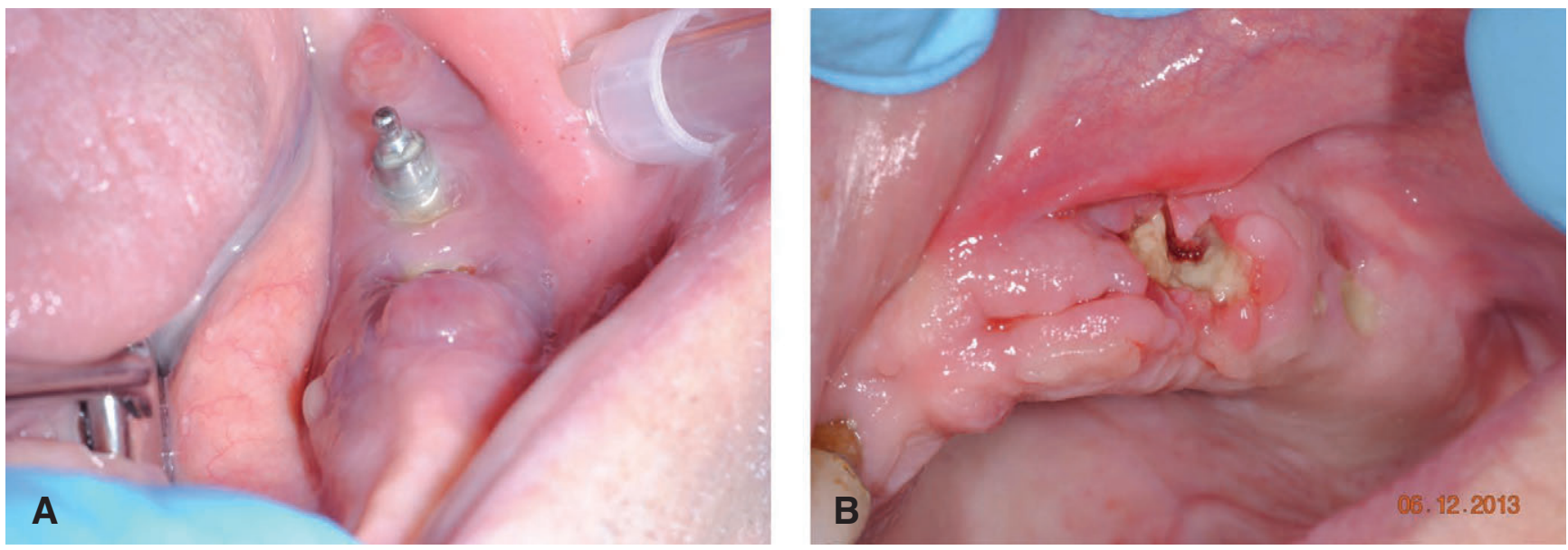

Figure 1. Example of MRONJ of mandible (A) and of maxilla (B). 
the application of platelet-enriched plasma at the site of osteonecrosis, bio stimulation with laser and oxygen-ozone therapy. 3,5,10-12,29 The results are interesting and need further investigations.

Oxygen-ozone therapy is a medical treatment based on the transfer of a mixture of oxygen and ozone in different quantities to the body using different techniques according to the treated pathology. Ozone $(\mathrm{O} 3)$ is a natural component of the atmosphere and it is very important for the ecological balance of the earth. In fact, it absorbs most of the ultraviolet radiation coming from the sun, preventing them from reaching the earth's surface directly (where they would determine the destruction of all life forms, as they are energy-rich). In medicine, it is produced by subjecting a medical oxygen $(\mathrm{O} 2)$ flow to high voltage. The reaction is reversible and the rate of dissociation from ozone to oxygen depends on the temperature. Ozone is an unstable gas that decays rapidly (the halflife of $\mathrm{O} 3$ at $+20^{\circ} \mathrm{C}$ is $40 \mathrm{~min}$ ). Therefore, it must be prepared extemporaneously in the doctor's surgery room. The gas used is always an oxygen/ozone mixture. ${ }^{22}$

Ozone has an indisputable and effective antiseptic activity. When in biological liquids and due to its oxidising capacity, ozone reacts with unsaturated fatty acids, with some proteins and with other reducing compounds generating $\mathrm{H}_{2} \mathrm{O}_{2}$ and a series of products including LOPs (lipid oxidation products).

For about hundred years, ozone has been used by doctors to treat a variety of symptoms such as: infectious diseases, immune dysfunction, joint pathologies, ischemic pathologies, neurodege-nerative pathologies and degenerative vascular diseases in ophthalmology. ${ }^{22,25}$

Ozone has a positive effect on both soft tissues and bone through the stimulation of endogenous antioxidants. It increases the concentration of red blood cells and haemoglobin, stimulates leukocyte diapedesis (diapedesis: passage of leukocytes from blood to tissues through the endothelial cells) and phagocytosis of the histiocytic reticulum system. ${ }^{3,22}$

Pre-clinical studies performed in animals suffering from periodontal disease, treated with in situ ozone infusion, showed a reduction in infection and inflammation. ${ }^{9}$

Some patients, treated with bisphosphonates for multiple myeloma, were given ozone, combined with antibiotic therapy, before and after dental surgery, with a clear reduction in the risk of developing MRONJ. ${ }^{10-13}$

Other authors have used ozone therapy with local infusions in MRONJ and they were successful concerning the stimulating effect and the antibacterial and analgesic properties. Ripamonti et al. (2011) proposed local applications of ozonated oil (with a custommade silicone-coated medical device) associated with antibiotic therapy with very encouraging effects. ${ }^{14}$

Agrillo et al. (2012) introduced ozone therapy in patients with MRONJ as a tissue-regenerating factor and suggests that this procedure could be considered a fundamental pre-and postoperative point to improve the patient's quality of life as the results confirm the efficacy of treatment in $90 \%$ of cases. ${ }^{7}$

Ozone therapy through the stimulation of cell proliferation promotes the formation of bone sequestration and soft tissue healing. ${ }^{7}$

The elimination of bone sequestration is the next step in the healing process and is handled with a surgical procedure which consists in removing dead, damaged or infected tissues (superficial debridement). ${ }^{24}$

Traditional bone surgery is performed with surgical drills mounted on rotating instruments that despite being at low speed $(15,000-40,000 \mathrm{rpm})$ run the risk of overheating the bone edge and compromising healing. ${ }^{27}$

Piezoelectric surgery is a new and innovative technique in bone surgery that uses a special device called piezoelectric scalpel. This scalpel produces ultrasonic pulses resulting in microscopic horizontal and vertical oscillations, capable of making a micrometric cut (vibrations between 24 and $37 \mathrm{kHz}$ with amplitude of 60 to $200 \mu \mathrm{m}$ and a power of 50 watt). ${ }^{27}$ The ultrasound waves do not only have a mechanical effect, they also have a thermal and cavitation effect on the tissues. By cavitation, we mean the formation of small gas bubbles generated by the ultrasonic pulses in the cooling liquid, which increase in volume until they burst. These very small gaseous bubbles increase the cut of the instrument and, when they burst, they displace oral fluids: the nebulised cooling liquid determines a bloodless field with maximum intra-operative visibility.

Another indisputable advantage is the reduction of bone suffering since piezoelectric surgery does not increase the temperature in the cutting area. This creates a favourable condition for a good recovery of the treated site.

The piezoelectric technique is also characterized by the selectivity of the cut. Indeed, the micro vibrations generated by the ultrasonic pulses are able to cut the mineralized tissues, with little or no effect on soft tissues. In this way, nerves or other anatomical structures are not damaged in the event of accidental contact.

Compared to milling tools mounted on the hand-piece, this technique has many advantages: less overheating of the bone, better healing, less pain for the patient, clear and well-defined lines of osteotomy, minimum risk of damaging healthy structures thanks to the micrometric and selective cut and absence of vibrations on the handpiece. ${ }^{27}$ To date, therefore, it seems that this technique should be predominant, especially in case of a significant risk of damaging adjacent nerve structures, injuring the surrounding soft tissues or further irritating the bone tissue. ${ }^{18-20}$

\section{Cases of medication-related osteonecrosis of the jaw at ASST Fatebenefratelli-Sacco}

Since 2010, I have visited and treated almost 500 patients at risk of osteonecrosis due to dental problems. I have diagnosed 51 cases of osteonecrosis.

Following the approval from the Ethics Committee, I have been authorised by my Company since the $27^{\text {th }}$ of April 2015 with the deliberation n. 327 to treat patients with osteonecrosis level 1 and 2 according to the experimental protocol Treatment of bisphosphonate-related osteonecrosis of the jaw with oxygen/ozone therapy and surgical debridement with piezoelectric scalpel.

The study aims to evaluate the antiseptic and bio stimulant abilities of ozone to reduce the osteonecrotic lesion by the delimitation and expulsion of the necrotic tissue (spontaneously or by debridement). Fourteen patients affected by osteonecrosis, who corresponded to the inclusion criteria, have been enrolled in the study. Patients have been treated twice a week for 10 weeks, for a total of 20 applications with the oxygen/ozone mixture. At the end of the $5^{\text {th }}$ week, a debridement operation has been performed: a medical procedure, performed under local anaesthesia, to remove the necrotic tissue using sterile instruments such as scissors, forceps, scalpel and piezoelectric scalpel.

The sessions were biweekly and the oxygen/ozone mixture has been applied:

i) With local submucosal infiltrations around the necrotic area and in the fistulas at the concentration of 10 micrograms $/ \mathrm{mL}$ using a $10 \mathrm{cc}$ syringe, with $29 \mathrm{~g}, 0.33 \times 13$ needle and the injections must be $2 / 3 \mathrm{cc}$ by inoculation up to a maximum of $15 \mathrm{cc}$;

ii) Using an individual device (ozone tray) at a concentration of 30 micrograms $/ \mathrm{mL}$ for 2 minutes. The ozone tray, custom-made using the alginate impressions taken from the oral cavity with osteonecrosis, includes an inlet hole and an outlet hole (Figure 2). 
The inlet is directly connected to the ozone generator (Multiossigen MEDICAL 99 IR) while the outlet is connected to the unit aspirator.

The comparison takes place through the analysis of clinical and radiographic parameters collected at the time points indicated in Table 2.

Patient number 6 presented two osteonecrotic lesions that were treated separately (Figure 3 ).
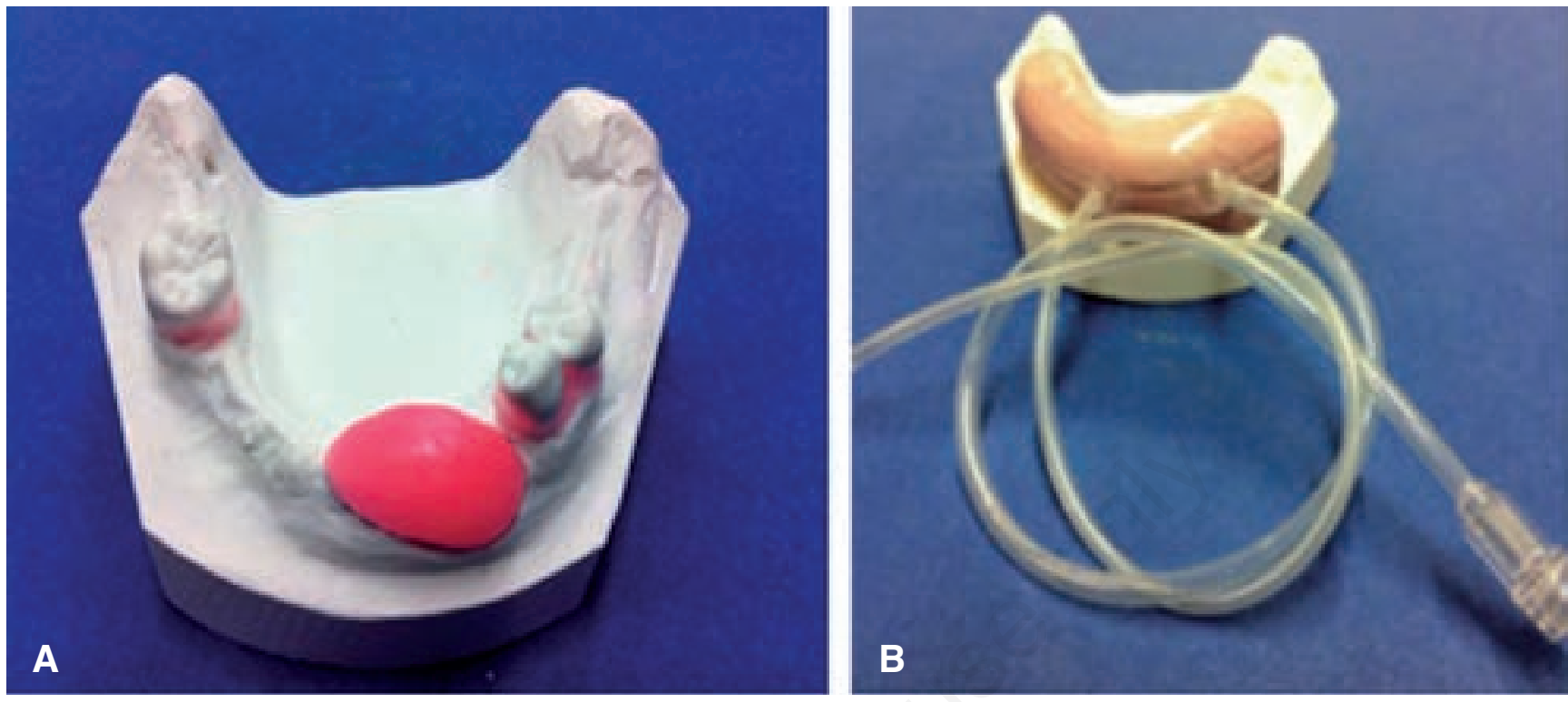

Figure 2. A) Construction step of custom-made ozone tray. B) Ozone tray.
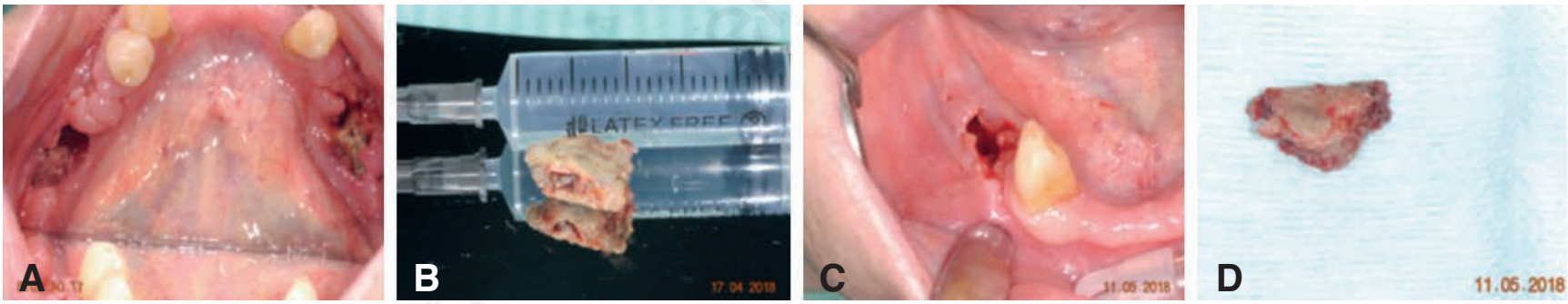

Figure 3. Patient n. 6. Two areas of osteonecrosis after the first month of treatment (A) where the left exposed bone was expelled (B); the second exposed bone (right) was expelled a month later (C and $D)$.

Table 2. Clinical and radiological parameters collected at specific time points $(\mathrm{w}=\mathbf{w e e k})$ for the selected patients.

\begin{tabular}{|c|c|c|c|c|c|c|c|c|c|c|}
\hline Variables & $\begin{array}{c}\text { T0 } \\
\text { Screen }\end{array}$ & $\begin{array}{c}\mathrm{T1} \\
2^{\text {nd }} \mathrm{W}\end{array}$ & $\begin{array}{c}\mathrm{T}^{\mathrm{th}} \\
5^{\text {th }} \mathrm{w}\end{array}$ & $\begin{array}{c}\mathrm{T} 2 \\
5^{\text {th }} w\end{array}$ & $\begin{array}{c}\text { T3 } \\
8^{\text {th }} w\end{array}$ & $\begin{array}{c}\text { T4 } \\
10^{\text {th }} \mathrm{w}\end{array}$ & $\begin{array}{c}\text { T5 } \\
12^{\text {th }} \mathrm{w}\end{array}$ & $\begin{array}{c}T 6 \\
24^{\text {th }} w\end{array}$ & $\begin{array}{c}\mathrm{T} 7 \\
48^{\text {th }} w\end{array}$ & $\begin{array}{c}\mathrm{T} 8 \\
96^{\text {th }} \mathrm{w}\end{array}$ \\
\hline Case history & $\mathrm{x}$ & & & & & & & & & \\
\hline Surgical debridement & & & & $\mathrm{x}$ & & & & & & \\
\hline Size of osteonecrosis & $\mathrm{x}$ & $\mathrm{x}$ & $\mathrm{x}$ & & $\mathrm{x}$ & $\mathrm{x}$ & $\mathrm{x}$ & $\mathrm{x}$ & $\mathrm{x}$ & $\mathrm{x}$ \\
\hline Oedema & $\mathrm{x}$ & $\mathrm{x}$ & $\mathrm{x}$ & & $\mathrm{x}$ & $\mathrm{x}$ & $\mathrm{x}$ & $\mathrm{x}$ & $\mathrm{x}$ & $\mathrm{x}$ \\
\hline Purulent material & $\mathrm{x}$ & $\mathrm{x}$ & $\mathrm{x}$ & & $\mathrm{x}$ & $\mathrm{x}$ & $\mathrm{x}$ & $\mathrm{x}$ & $\mathrm{x}$ & $\mathrm{x}$ \\
\hline Degree of pain: VAS (0-10) & $\mathrm{x}$ & $x$ & $\mathrm{x}$ & & $\mathrm{x}$ & $\mathrm{x}$ & $\mathrm{x}$ & $\mathrm{x}$ & $\mathrm{x}$ & $\mathrm{x}$ \\
\hline EORTC QL30 Questionnaire & $\mathrm{x}$ & & $\mathrm{x}$ & & & $\mathrm{x}$ & & & $\mathrm{x}$ & $\mathrm{x}$ \\
\hline Orthopantomography (OPT) & $\mathrm{x}$ & & & & & & $\mathrm{x}$ & & $\mathrm{x}$ & $\mathrm{x}$ \\
\hline C.A.T. scan & $\mathrm{x}$ & & & & & & $\mathrm{x}$ & & $\mathrm{x}$ & $\mathrm{x}$ \\
\hline Adverse events & & $\mathrm{x}$ & $\mathrm{x}$ & $\mathrm{x}$ & $\mathrm{x}$ & $\mathrm{x}$ & $\mathrm{x}$ & $\mathrm{x}$ & $\mathrm{x}$ & $\mathrm{x}$ \\
\hline
\end{tabular}

$\mathrm{X}=$ parameter value collected. ${ }^{*}$ During $5^{\text {th }}$ week, surgical debridement is performed after the evaluation of selected parameters. 
Until now, six patients healed perfectly and among these, four expelled spontaneously or almost spontaneously the necrotic part without undergoing surgery. In three cases, there was only an improvement in symptoms. Five patients are currently being treated.
To conclude, thanks to its antiseptic properties, oxygen/ozone therapy reduced the effects of infection and inflammation, while the bio stimulant action of this therapy promoted the demarcation of bone sequestration and soft tissue healing (Figures 3-7).
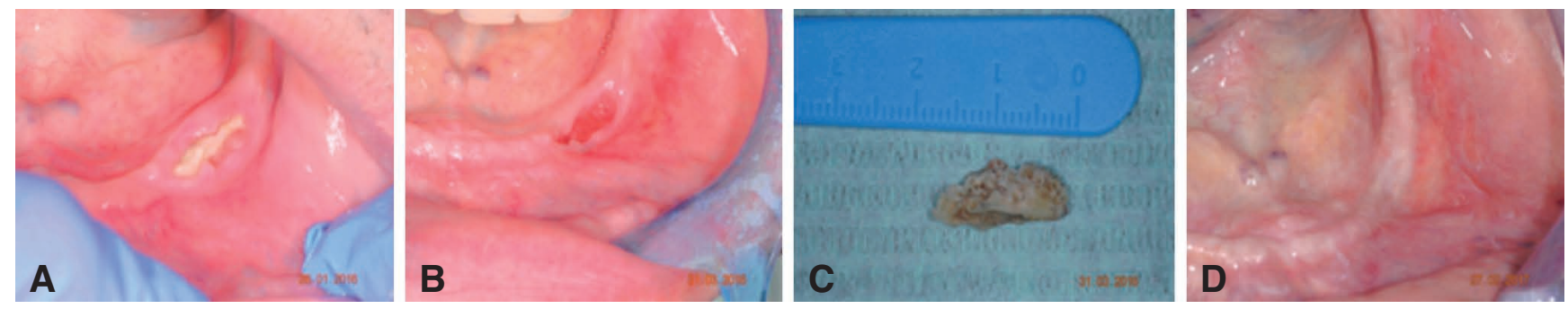

Figure 4. Patient n. 2. Osteonecrosis before treatment (A); after the $5^{\text {th }}$ application (B), the exposed bone was spontaneously expelled (C); complete recovery (D).
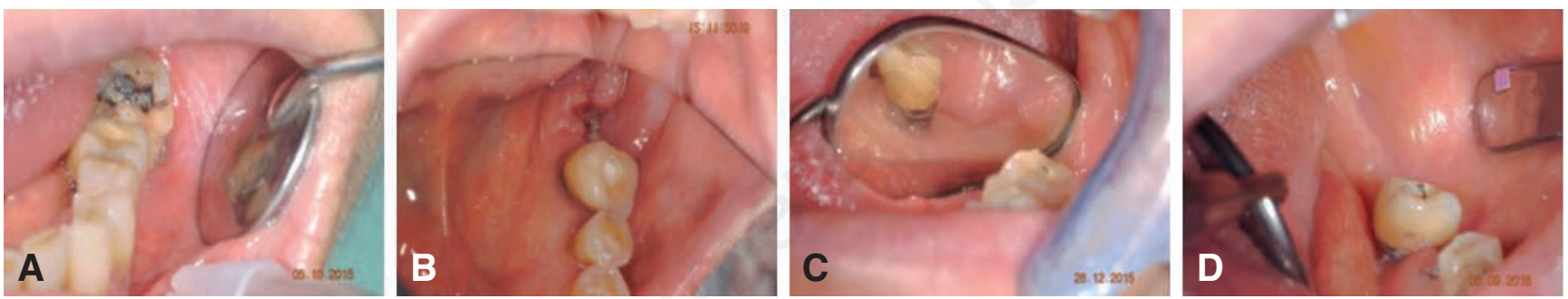

Figure 5. Patient n. 1. Osteonecrosis before treatment (A); 10 days (B) and 30 days (C) after surgical debridement; (D) final follow-up visit after 3 years showing complete recovery.
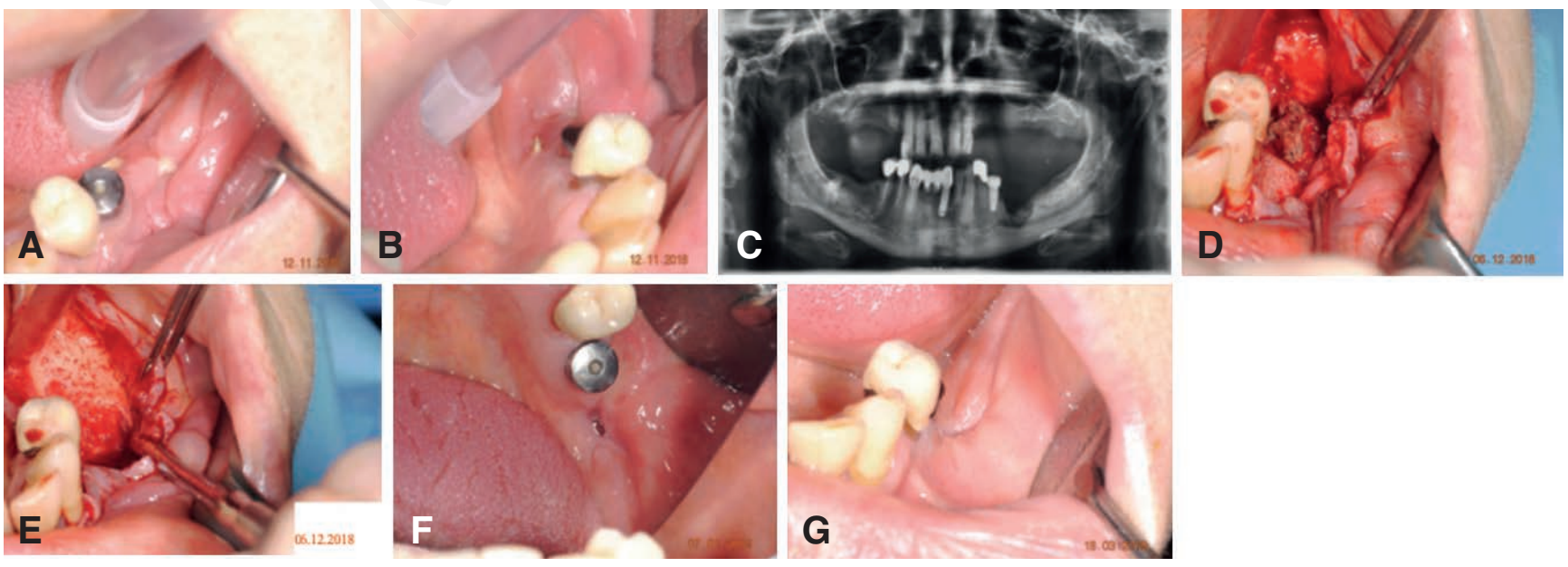

Figure 6. Patient n. 8. Osteonecrosis before treatment (A, B and X-ray image in C); surgical debridement (D and E); appearance of treated area one month after the surgical debridement $(F)$; final recovery $(G)$. 


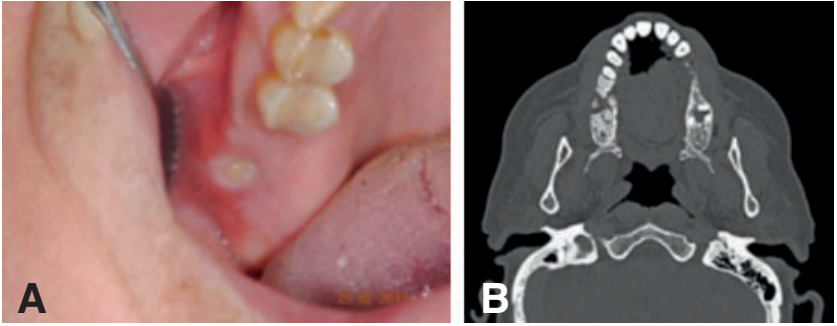

Figure 7. Patient n. 10. Osteonecrosis before treatment (A) with $\mathrm{X}$-ray image $(\mathrm{C})$.

\section{References}

1. Mavrokokki T, Cheng A, Stein B, Goss A. Nature and frequency of bisphosphonate-associated osteonecrosis of the jaws in Australia. J. Oral. Maxillofac. Surg. 2007;65: 415-23.

2. Marx RE. Pamidronate (Aredia) and zoledronate (Zometa) induced avascular necrosis of the jaws: a growing epidemic. J Oral Maxillofacial Surg 2003;61:115-7.

3. Vescovi N. Bisphosphonate-Related Osteonecrosis of the Jaw (BRONJ) therapy. Acritical review. Minerva Stomatola 2010;59:181-213.

4. Osteonecrosi dei mascellari (ONJ) 2009: Prevenzione, Diagnosi e Trattamento UPDATE, Torino 23 giugno 2009.

5. Osteonecrosi dei mascellari (ONJ) 2010: Prevenzione, Diagnosi e Trattamento UPDATE, Torino 05 giugno 2010.

6. Position Paper on Bisphosphonate-Related Osteonecrosis of the Jaw-2009 Update. Approved by the Board of Trustees January 2009.

7. Agrillo A, Filiaci F, Ramieri V, et al. Bisphosphonate-related osteonecrosis of the jaw (BRONJ): 5 year experience in the treatment of 131 cases with ozone therapy. Eur Rev Med Pharmacol Sci 2012;16:1741-7.

8. Filleul O, Crompot E, Saussez S. Bisphosphonate- induced osteonecrosis of the jaw: a review of 2,400 patient cases. J Cancer Res Clin Oncol 2010;136:1117-24.

9. Grigor'ian AS, Grigor'iants LA, Guchetl MN. Experimentalmorphological study of the anti-inflammatory action of ozone-perfluorane complex application. Stomatologiia 2008;87:4-9.

10. Agrillo A, Petrucci MT, Tedaldi M, et al. New therapeutic protocol in the treatment of avascular necrosis of the jaws. J Craniofac Surg 2006;17:1080-3.

11. Agrillo A, Sassano P, Rinna C, et al. Ozone therapy in extractive surgery on patients treated with bisphosphonates. J Craniofac Surg 2007;18:1068-70.

12. Agrillo A, Ungari C, Filiaci F, et al. Ozone therapy in the treatment of avascular bisphosphonate-related jaw osteonecrosis. J Craniofac Surg 2007;18:1071-5.

13. Petrucci MT, Gallucci C, Agrillo A, et al. Role of ozone therapy in the treatment of osteonecrosis of the jaws in multiple myeloma patients. Haematologica 2007;92: 1289-90.

14. Ripamonti CI, Cislaghi E, Mariani L, Maniezzo M. Efficacy and safety of mediacal ozone $(\mathrm{O} 3)$ delivered in oil suspension appliations for the treatment of osteonecrosis of the jaw in patients with bone metastases treated with bisphosphonates: Preliminary results of phase I-II study. Oral Oncol 2011;47:185-90.

15. Schultz GS. Wound bed preparation: a systematic approach to wound management. Wound Repair Regen 2003;11:1-28.

16. Clinical Practice Guideline Number 15: Treatment of Pressure Ulcers. AHCPR publication 95-06542. Rockville, Md: US Dept of Health and Human Services, Agency for Health Care Policy and Research; 1994.

17. Attinger CE, Janis JE, Steinberg J, et al. Georgetown Clinical approach to wounds: débridement and wound bed preparation including the use of dressings and wound-healing adjuvants. Washington, DC: Limb Center, Georgetown University Medical Center; 2007.

18. Shanghai Kou Qiang Yi Xue. Development and clinical application of ultrasonic osteotomy in dentistry. Rev Stomatol Chir Maxillofac 2007;108:431-40.

19. Peivandi A, Bugnet R, Debize E, et al. [Piezoelectric osteotomy: applications in periodontal and implant surgery]. Oral Surg Oral Med Oral Pathol Oral Radiol Endod 2009;108:360-7. [Article in French].

20. González-García A, Diniz-Freitas M, Somoza-Martín M, García-García A. Ultrasonic osteotomy in oral surgery and implantology. Oral Surg Ora Med Oral Pathol Oral Radiol Endod 2009;108:360-7.

21. Petrucci MT, Gallucci C, Agrillo A, et al. Role of ozone therapy in the treatment of osteonecrosis of the jaws in multiple myeloma patients.

22. Bocci V. Ossigeno - ozonoterapia. Rozzano (MI): Casa Editrice Ambrosiana; 2000.

23. Schultz GS, Sibbald RG, Falanga V, et al. Wound bed preparation: a systematic approach to wound management. Wound Repair Regen 2003;11:1-28.

24. Somà K, Furlini S. Gestione della carica necrotica: Debridement chirurgico. VI Congresso Nazionale AIUC Genova 12-15 Settembre 2007.

25. Stübinger S, Sader R, Filippi A. The use of ozone in dentistry and maxillofacial surgery: a review. Quintessence Int 2006;37:353-9.

26. Valente A, Raffaelli L, Manicone P, D'addona A. Influenza della piezochirurgia nel decorso intra e postoperatorio. Risultati preliminari. Dental Cadmos 2010;78:9.

27. Pistilli R, Bailo A. La chirurgia ultrasonica nella riabilitazione di mandibole atrofiche. Dental Clinics 2009;III:4.

28. Ministero del Lavoro, della Salute e delle Politiche sociali. Raccomandazione n. 10, settembre 2009

29. Bedogni A, Campisi G, Fusco V, Agrillo A. Raccomandazioni clinico-terapeutiche sull'osteonecrosi delle ossa mascellari associata a bifosfonati e sua prevenzione. Padova: Coop. Libraria Editrice Università di Padova; Marzo 2013.

30. Chang J, Hakam AE, McCauley LK. Current Understanding of the Pathophysiology of Osteonecrosis of the Jaw. Current Osteopor Rep 2018;16:584-95.

31. Fassio A, Bertoldo F, Idolazzi L, et al. Drug-induced osteonecrosis of the jaw: the state of the art. Reumatismo 2017;69:9-15

32. Raccomandazioni del Ministero della Salute. Raccomandazioni per la promozione della salute orale, la prevenzione delle patologie orali e la terapia odontostomatologica nei pazienti adulti con malattia neoplastica; 2014.

33. Leoni O, Conti V, Magistro L, Rivolta AL. L'uso dei “farmaci per il trattamento delle malattie delle ossa" in Lombardia: 
analisi di farmacovigilanza e farmacoutilizzazione. Milano: Centro Regionale di Farmacovigilanza Regione Lombardia, Scuola di Specializzazione in Farmacologia Medica, Università degli Studi di Milano; 2017.
34. Ruggiero SL, Dodson TB, Fantasia J, et al. American Association of Oral and Maxillofacial Surgeons position paper on medication-related osteonecrosis of the jaw - 2014 update. J Oral Maxillofac Surg 2014;72:1938-56. 